\title{
Chlorella vulgaris, a microalgae important to be used in Biotechnology: a review
}

\author{
Jesús Alberto CORONADO-REYES ${ }^{1}$, Juan Alfonso SALAZAR-TORRES ${ }^{1}$, Beatriz JUÁREZ-CAMPOS ${ }^{1}$ \\ and Juan Carlos GONZÁLEZ-HERNÁNDEZ ${ }^{1 *}$
}

\begin{abstract}
Chlorella vulgaris is a microalgae belonging to the order of the Chlorococcales, of the Oocytaceae family, of the genus Chlorella, which has a green colour due to the chloroplasts it contains. Its shape is spherical with a size that varies from 1 to 10 microns. These microalgae contain, in addition to chlorophyll, a significant amount of intracellular proteins, carbohydrates, lipids, vitamin $\mathrm{C}, \beta$-carotenes and B vitamins (B1, B2, B6 and B12), which is why it is commonly used for the preparation of food supplements, as well as for the production of cosmetics, clinical treatments and even for the detoxification of heavy metals in wastewater. For this reason, the following review speaks from the morphology of the microalgae $C$. vulgaris to recent investigations regarding the primary and secondary metabolites. This research also provides an overview of the areas of opportunity for the development of new products and process improvements in order to increase the existing yields so far to optimize responses based on the desired products, the formulation of various growth media or the design of new photobioreactors which allow greater control of growth conditions and easy scaling for high productions at the industrial level that cover the current global needs.
\end{abstract}

Keywords: composition, growing, metabolites, applications.

Practical application: With the analysis of the morphology of the microalgae, their metabolism, reproduction and the investigations that have been carried out regarding the primary and secondary metabolites that they produce during their growth and the abiotic factors that are important during growth is possible propose designs optimization of cell growth of the C. vulgaris species with which the yields of biomass and metabolites in crops can be increased at the photobioreactor level.

\section{Introduction}

The study of microalgae has become important in recent years because they are considered as raw materials for chemical compounds that have been affected by their primary and secondary metabolism, such as lipids, whose main application is for the generation of biodiesel. Among the advantages that the use of microalgae has at an industrial level, it can be identified that their cultivation is easy and fast, since they can complete their growth cycle in a few days and can develop both in salt water and freshwater in ponds., forests, and even once in fermentation tanks, have also been found to grow in wastewater ( $\mathrm{Lu}$ et al., 2015). The C. vulgaris strains are species of microalgae that grow easily and quickly where, based on their metabolism, the culture medium can be autotrophic, heterotrophic, mixotrophic and photobioreactor, observing that the highest concentration of biomass is genres when working in a mixotrophic medium or photobioreactor level, so it is interesting to analyze the growth of $C$. vulgaris in a mixotrophic medium using a photobioreactor. Among the applications that can be given to the metabolites produced by $C$. vulgaris is the production from the lipids that it produces as well as the synthesis of proteins and some carbohydrates (Ardila-Álvarez et al., 2017).

\subsection{Morphology}

C. vulgaris is a microscopic organism with a size of 2 to $10 \mu \mathrm{m}$ and with a structure similar to that of higher plants, because it contains; a cell wall, mitochondria, and chloroplasts, the latter being necessary to carry out photosynthesis(Safi et al., 2014).

Regarding the cell wall, it is the main defense against biotic and abiotic factors of the microalgae. At the beginning of the cell wall formation, its thickness is approximately $2 \mathrm{~nm}$ and as the microalgae matures, the thickness increases until it reaches a thickness of $21 \mathrm{~nm}$ (Yamamoto et al., 2004). As for the mitochondria, it can be mentioned that they are in charge of carrying out the metabolic processes with which the microalgae will obtain its energy, necessary to carry out all the growth and maintenance processes. The mitochondria of $C$. vulgaris are made up of double membranes, proteins and phospholipids. Finally, C. vulgaris only contains a single chloroplast which is composed of phospholipids and consists of two membranes where the first is permeable to certain metabolites and some ions, but the second membrane is highly selective and its function is the transport of proteins. In addition to this function, the synthesis of starch granules is possible within the chloroplast (Safi et al., 2014). Within the chloroplasts are the thylakoids where the chlorophyll is found, with which it is possible to capture energy through radiation and that it is used by the organism to create its own food. The following Figure 1 shows the $C$. vulgaris morphology.

As can be seen in Figure 1, C. vulgaris have a defined spherical shape and the amount of chlorophyll and pigments contained in them makes it possible to observe the living cells that keep their 
cell wall intact under a microscope. When the cells are affected and are in a state of death, it is possible to observe how the cell wall has been affected and the inner color of the microalgae changes to a dark green (Coronado-Reyes, 2020).

C. vulgaris is a microalgae that in its growth medium has both an isolated and an individual organization, as well as being capable of forming colonies with a maximum of up to 64 cells as shown in Figure 2 below. In addition to the above C. vulgaris is a microorganism that does not have limbs that allow it mobility in its growth medium (Kai et al., 2020).

C. vulgaris, as can be seen in Figure 2, can sometimes be grouped in clusters in such a way that it can create a favorable environment for its growth; however, it has been observed that this type of organization can be favorable for the precipitation of the microalgae and thus purify it from the growth medium to later give it a utility, but it is also unfavorable for counting cells at the microscope level since it prevents the identification correctly the number of living cells and the total amount that make up the cluster, so it is recommended that for cell division monitoring, avoid generating it (Coronado-Reyes, 2020).

\subsection{Reproduction}

The type of reproduction of the microalgae is asexual and it is by self-sporulation that it takes around 24 hours to perform its division. Cell division consists of 6 steps, which include; 1) increase in cell size, 2) formation of the inner cell wall for the daughter cell, 3) division of the chloroplast into 2,4) second division of chloroplasts to form 4,5 ) formation and maturation of the daughter cell wall. Division of the 4 new cells and 6) Cell rupture of the old wall for the release of the 4 daughter cells (Safi et al., 2014). It is important to mention that this process is

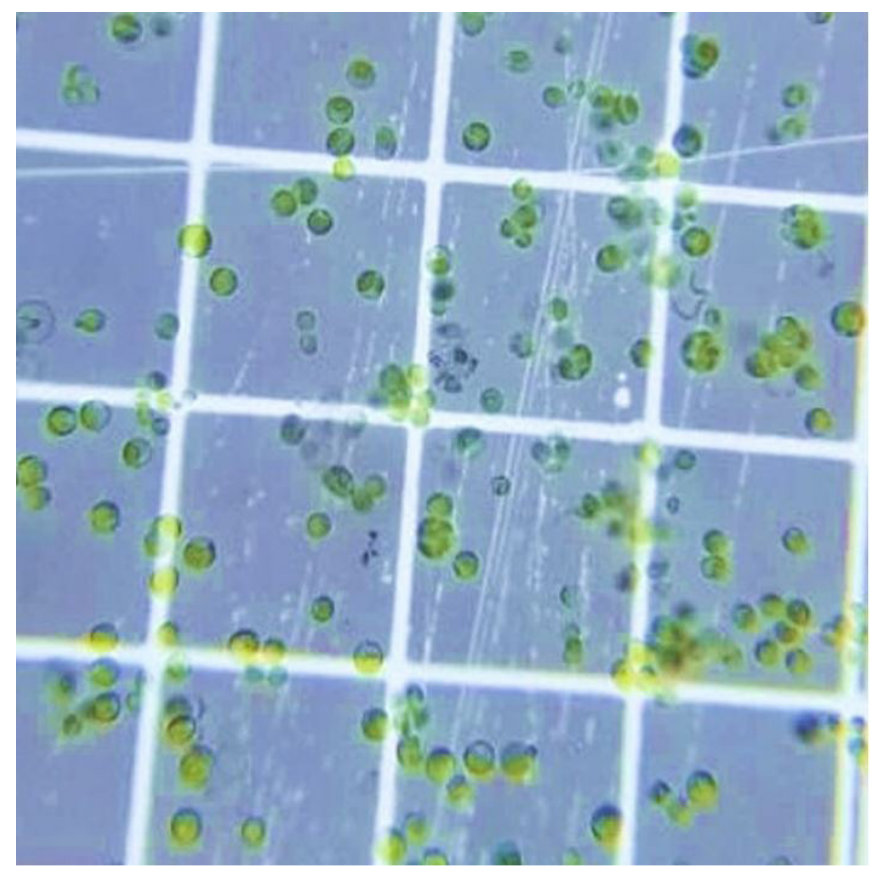

Figure 1. C. vulgaris morphology (Taken and modified from CoronadoReyes, 2020). carried out as long as the cell is in favorable growth conditions since if it is subjected to stress it can have a longer growth time.

\subsection{Chemical composition}

The composition of the C. vulgaris microalgae in the biomass generated during the growth kinetics have allowed the identification of some of the synthesized primary metabolites such as: proteins, lipids and carbohydrates, as well as some pigments resulting from secondary metabolism. In general, $C$. vulgaris is constituted as follows, as is showed in the next Table 1:

Within this general composition presented in Table 1, it is possible to observe that of the dry weight in the biomass generated, a large part of the content is protein, which is why it can give great nutritional value. With the general composition in the same Table 1, so much works have been carried out to delve into what specific type of metabolites constitute C. vulgaris, therefore a complete analysis of each of the chemical fractions analyzed so far is presented below:

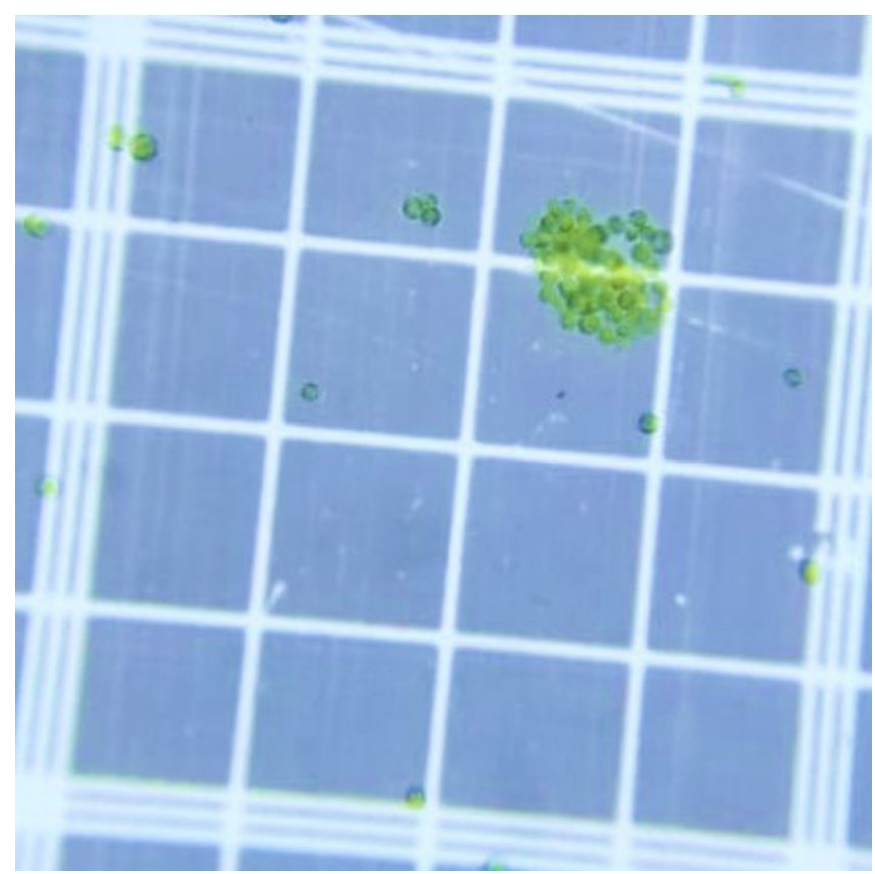

Figure 2. Kind of C. vulgaris organization (Taken and modified from Coronado-Reyes, 2020).

Table 1. C. vulgaris chemical composition (Taken and modified from Mohamed et al., 2013).

\begin{tabular}{lr}
\hline \multicolumn{1}{c}{ Component } & $(\%)$ \\
\hline Moisture & 5.83 \\
Dry matter & 94.17 \\
Crude protein & 51.45 \\
Carbohydrates & 11.86 \\
Crude lipid & 12.18 \\
Crude fiber & 9.18 \\
Ash & 9.50 \\
\hline
\end{tabular}




\section{Proteins}

The total protein composition in C. vulgaris represents between $42-58 \%$ of the dry weight in the biomass generated. Of which close to $20 \%$ are adhered to the cell wall serving a structural and transport role for the cell, $50 \%$ are intracellular proteins with their function as enzymes mostly and the remaining $30 \%$ are secreted into the extracellular medium where they are develops the microalgae. The total weight of the proteins ranges from 12 to $120 \mathrm{kDa}$ (Kilo daltons) where the vast majority is in the range of 39 to $75 \mathrm{kDa}$. C. vulgaris is important at a nutritional level since in autotrophic or heterotrophic media they have the ability to synthesize essential and non-essential amino acids for humans. Both the proteins and the amino acids present in the growth medium can be extracted using alkaline solutions, ultrafiltration or by their precipitation with trichloroacetic acid or $0.1 \mathrm{~N}$ hydrochloric acid (Safi et al., 2014).Among the amino acids that have been characterized in the growth kinetics of C. vulgaris are: aspartic acid, threonine, serine, glutamic acid, glycine, alanine, cysteine, valine, methionine, isoleucine, leucine, tyrosine, phenylalanine, histidine, lysine, arginine, tryptophan, ornithine and proline, where glutamic acid is the one that is synthesized with the greatest abundance followed by aspartic acid with a concentration of $13.7 \mathrm{~g} / 100 \mathrm{~g}$ of protein and $10.94 \mathrm{~g} / 100 \mathrm{~g}$ of protein respectively (Ursu et al., 2014).

Within the composition of the amino acids identified in the biomass of this microalgae are some essentials such as: histidine, isoleucine, leucine, lysine, methionine, phenylalanine, threonine and valine, with the exception of tryptophan (Mohamed et al., 2013). The amino acids identified in C. vulgaris are shown in Table 2 below:

As can be seen in Table 2, C. vulgaris contains a large amount of essential amino acids and where aspartic acid together with glutamic acid are those that contain a greater proportion, so it can be given great nutritional value to foods containing this microalgae.

Lipids

They constitute from 5 to $40 \%$ of the dry weight in the biomass, being mainly glycolipids, waxes, hydrocarbons, phospholipids and fatty acids, which are synthesized in the chloroplasts and once synthesized they are directed to the cell walls and membranes of the different organelles as the chloroplasts themselves and the mitochondria. When C. vulgaris grows in an unfavorable environment, lipid production is favored, reporting up to $58 \%$ of the total composition of the microalgae, located between the space of the thylakoids in the chloroplasts (Montero-Sánchez et al., 2012).

Within the lipid profile that has been carried out in C. vulgaris, a higher concentration of fatty acids of 18 and 16 carbon atoms have been found, as presented in Table 3 below:

In Table 3 above, it can be seen that the fatty acids contained are not short-chain and that most of them have 18 carbon atoms, where all of the aforementioned are favorable for health if consumed (Montero-Sánchez et al., 2012).
Regarding the type of fatty acids in C. vulgaris, it has been identified that $70.18 \%$ corresponds to saturated fatty acids (SFA), $16.85 \%$ corresponds to monounsaturated fatty acids (MUFA) and finally $8.72 \%$ corresponds to polyunsaturated fatty acids (PUFA) so it gives a wide variability in its lipid profile (Shanmugam et al., 2020).

\section{Carbohydrates}

They are present in the form of starch and cellulose, as well as some reducing sugars. Starch is found in chloroplasts consisting mainly of amylose and amylopectin. Cellulose is part of the cell wall of $C$. vulgaris whose glycosidic bond is $\beta 1-3$, therefore it can be used as an input for the elaboration of functional products that contribute to human health. For the identification and characterization of the sugars present in C. vulgaris, the use of HPLC is recommended and with which it has been identified that the composition of the cell walls of the microalgae results from

Table 2. Amino acids characterization in C. vulgaris (Taken and modified from Mohamed et al., 2013).

\begin{tabular}{lc}
\hline Amino acids: concentration (g/100 g protein) & \\
\hline Aspartic acid & 10.5 \\
Threonine & 5.24 \\
Serine & 5.08 \\
Glutamic acid & 10.74 \\
Glycine & 5.1 \\
Alanine & 8.44 \\
Valine & 6.44 \\
Methionine & 1.5 \\
Isoleucine & 5.01 \\
Leucine & 6.84 \\
Tyrosine & 5.2 \\
Phenylalanine & 4.2 \\
Histidin & 5.02 \\
Lysine & 5.6 \\
Arginine & 8.2 \\
Proline & 6.4 \\
$\mathrm{NH}_{4}$ & 6.4 \\
\hline
\end{tabular}

Table 3. Fatty acids composition in C. vulgaris (Taken and modified from Shanmugam et al., 2020).

\begin{tabular}{lcr}
\hline Fatty acids & Carbon number & $(\%)$ \\
\hline Palmitic cid methyl ester & C16:0 & 17.5 \\
Palmitoleic acid methyl ester & C16:1 & 3.27 \\
Stearic acid methyl ester & C18:0 & 15.39 \\
Oleic acid methyl ester & C18:1 & 13.87 \\
Linolelaidic acid methyl ester & C18:2n6 & 9.18 \\
Lignoceric acid methyl ester & C24:0 & 22.11 \\
\hline
\end{tabular}


a mixture of rhamnose, galactose, glucose, xylose, arabinose and mannose where the most abundant is rhamnose (Ho et al., 2011).

\section{Pigments}

Among the most abundant pigments in C. vulgaris is chlorophyll, which makes up 1 to $2 \%$ of the biomass dry weight. In addition to these pigments, there is also the presence of carotenoids which belong to the group of secondary metabolites called terpenes. The carotenoids identified in the microalgae are essentially $\beta$-carotenes that are associated with the lipids present in the chloroplasts, as well as with chlorophylls and thylakoids in the chloroplasts themselves. The identified pigments have been evaluated for their antioxidant activity, which have been reported to be extracted using solvents such as; dimethylformamide, dichloromethane, acetone, hexane and ethanol through methods such as Soxhlet, assisted extraction by ultrasound and with supercritical fluids. Among the main pigments that have been identified in $C$. vulgaris are: $\beta$-carotenes, astaxanthin, canthaxanthin, lutein, chlorophyll a and b, pheophytin a and $\mathrm{b}$ and violoxanthin. As it can be observed, there is presence of some polyphenols such as luteolin, so it would be possible to use other solvents with which it is possible to evaluate and characterize if there are others (Ohse et al.,2008).

\subsection{Culture}

\section{Autothophic growth}

The autohophic metabolism is carried out naturally by superior plants and microalgae, where it obtains the energy necessary for the synthesis of new chemical compounds through the radiation of sunlight or a similar energy source. Energy will be necessary so that together with the inorganic carbon such as $\mathrm{CO}_{2}$, the construction of complete molecules necessary for the survival of the special can be done (Andrade et al., 2014).

\section{Heterthophic growth}

This type of growth does not take the energy required for the growth of the microalgae from a light source, but rather from organic carbon sources such as sugars or some fats such as glycerol or compounds such as different types of acetates or glutamates. It has been observed that under this form of growth, the biomass yield generated is higher than that observed in the autotrophic media, making it a convenient way to duplicate C. vulgaris (Morales-Sánchez et al., 2014).

\section{Mixothophic growth}

C. vulgaris has the ability to grow in a medium where the conditions mentioned above are agreed, that is, autotrophic and heterotrophic growth, which makes them not dependent on the energy absorbed from light or from organic carbon sources. Under this growth condition, a higher yield has been observed compared to the other two media, which is explained by the fact that in the autotrophic growth medium, during the dark phase, there is no energy supply that allows the synthesis of metabolites for cell division, so the cell must wait for light to absorb energy again; however, by having a medium with an organic carbon source, the cell can continue to obtain energy and continue its growth (Moon et al., 2013). That is why it is recommended to work under this medium at the time of cultivation of C. vulgaris since biomass concentrations around 2 to $5 \mathrm{~g} / \mathrm{L}$ per day of growth have been reported (Safi et al., 2014).

\subsection{Factors influencing growth}

C. vulgaris has been shown to be a species of microalgae with which high yields of primary and secondary metabolites can be had; However, it has been observed that, due to its adaptability, it can respond differently when exposed to different factors during its growth, which is why the ones evaluated so far and the influence it has on the growth of the microalgae (Casierra-Posada, 2007).

\section{Light}

As it is a photosynthetic organism, the production and efficiency of the phenomenon is strongly related to the light of which the important thing is its intensity. When photosynthetic organisms do not have organic carbon sources, their main way of obtaining energy is through light, which as the intensity increases, the products generated from photosynthesis also increase; However, there is a maximum point at which organisms absorb energy and if this point is exceeded, a phenomenon known as photoinhibition is suffered (Seyfabadi et al., 2011) which is defined as the inhibition of photosynthesis due to excess radiation that directly affects production, indicating that the photosynthetic organism is under stress. Photo inhibition may be reversible (Casierra-Posada, 2007).

In addition to the negative effect that exposure to high light intensities can cause on the microalgae, photosynthetic products can be affected by another phenomenon with respect to light throughout growth, which is called "self-shading" where the cells that They are close to the light source, they carry out photosynthesis without any problem, but they will gradually shade the cells that are posterior to them, so the growth is inhibited, it is for them that it is recommended that the growth medium is instrumented in such a way that it allows the cellular circulation so that the cells can be in as uniform a contact as possible with the light source. The recommended for this circulation is the movement induced by bubbling in the tank and the use of blades is not recommended since they can damage the cells (Contreras et al., 2003).The path of light must also be considered during the growth of the microalgae, this path is defined as the transverse distance that a photon must travel to pass through a system such as a photobioreactor in such a way that the path of the light will be determined by the depth of liquid in a reactor (Contreras et al., 2003).

\section{Temperature}

For an organism to grow it is necessary that the environment in which it develops is favorable and temperature is undoubtedly one of the main factors, each organism is different so they have different temperature ranges in which they can grow and others with those who die. The ideal cell growth temperature of an 
organism is known as the optimal growth temperature. For the Chlorella species microalgae, the optimum temperature ranges from 28 to $35^{\circ} \mathrm{C}$. In the event that the temperature is below those indicated, the microalgae is not able to grow since its metabolic system is stopped, but when the temperature is exceeded, plant respiration begins, that is, instead of $\mathrm{CO}_{2}$ fixation begins to fix $\mathrm{O}_{2}$ and therefore the production of primary and secondary metabolites is reduced (Chinnasamy et al., 2009).

$p H$

Microalgae can normally grow at a $\mathrm{pH}$ around 8 , and it is important to stay close as a variation significantly affects biomass production. Among the factors that can alter the environment are; cellular respiration, alkalinity of nutrients at the time of preparing the culture medium, autotrophic and heterotrophic microbial activity, as well as the concentrations of $\mathrm{CO}_{2}$ dissolved in the medium since if it accumulates and is not fixed by the microalgae, the medium becomes alkaline (Bartley et al., 2013).

\section{$\mathrm{O}_{2}$ and $\mathrm{CO}_{2}$}

During photosynthesis, part of the products formed is oxygen, so it has been observed that the concentration of oxygen in the medium can increase from $200 \%$ to $300 \%$, however this increase causes the production of biomass and metabolites to be seen significantly affected since the organism can enter a process of respiration, as previously indicated, and stop producing the molecules of interest. Within the decrease in the production of metabolites and biomass it ranges from $17 \%$ to $25 \%$, so this parameter must be controlled during growth kinetics (Acién Fernández et al., 2012). Regarding the supply of $\mathrm{CO}_{2}$ and its fixation, it is necessary that at optimal growth temperatures the same gas supply is made since this will better dissociate in the medium and can be absorbed by organisms in an aqueous medium and thus carry out photosynthesis.

\section{Nutrients}

The main nutrient that the microalgae requires for its growth is nitrogen since it will obtain genetic material and proteins and even lipid synthesis. Microalgae fix nitrogen from two molecules; nitrates or ammonia. The culture medium can have carbohydrates when working with photoheterotrophic medium where these molecules will be the sources of carbon and not mainly $\mathrm{CO}_{2}$, and finally it is recommended that the culture medium be enriched with phosphorus since from this the microalgae will have Atoms necessary for the synthesis of nucleic acids and energy molecules such as ATP. Phosphorous sources can be incorporated into the medium in the form of phosphates and where a concentration above $1 \%$ per liter of prepared medium is recommended (Grobbelaar, 2004).

\subsection{Instruments culture}

For the cultivation of microalgae, two growth systems can be used in general; open systems and closed systems. If for this reason for the designs of any of both systems it is important to consider the following factors: biological study model, form of cultivation, nutrient requirements, light source, culture volume, supply and dispersion of gases, resistance of involved materials, temperature regulation, arrangement and orientation and cost analysis.

Each of these factors must be taken into account in order to establish what is best adapted to the growth of the microalgae and above all, it is possible to achieve the expected biomass yields (Hernández-Pérez \& Labbé,2014).

\section{Open systems}

This type of system is the simplest and most common, which implies low cost of construction and operation although they are durable. Basically, they are large places where the microalgae are contained and they are allowed to grow under environmental conditions, taking care only that they are in circulation or movement that are in contact with the nutrients in the medium and do not precipitate in the bottom of the tanks. Among the disadvantages that these systems present, it can be mentioned that the cells most of the time are not in constant contact with light, which reduces the efficiency of photosynthesis, evaporation of the culture medium, large dimensions in the required constructions of the systems and danger from contamination by other organisms, therefore they are only recommended for species that are resistant (Godos et al., 2009).

\section{Closed systems}

In this type of system it is possible to have greater control over the cultivation conditions than open systems, in addition to the fact that a higher biomass production has been observed at the same time that polluting agents are prevented and where mainly the light can be of an artificial type, solar or both. In this type of photobioreactors the culture systems can be; with bubble columns, airlift columns, agitated, conical and tubular helical tanks and where the main advantage is that there is greater control of the experimental conditions, ease of sterilization, simple acclimatization and reduction of photo-oxidation, however they are more expensive of open systems (Kunjapur \& Eldridge, 2010):

\subsection{Applications}

\section{Metabolites primary or secondary production}

C. vulgaris is mainly used for biomass production, which is used as a source of fiber due to the type of carbohydrates it contains, however, it is also used for the synthesis of proteins and lipids, so it is important to evaluate under what conditions there are higher production depending on the growth conditions that have a major influence, that is why was evaluated the production of biomass and lipids under these different growth media, for which, in the autotrophic medium, the cells were grown in a $1000 \mathrm{~mL}$ liquid medium with an air flow of $200 \mathrm{~mL} / \mathrm{min}$ under constant fluorescent light. where the concentration of $\mathrm{NaNO}_{3}$ in the medium was varied to see the effect since this is an important salt as a source of nitrogen in the medium. For the heterotrophic culture, three different carbon sources were used, which were: glucose, acetate and glycerol, at which the concentration of 
$\mathrm{NaNO}_{3}$ in the culture medium was varied, as well as the effect of light. It should be noted that the kinetics were carried out over 12 days, where biomass was taken into account for the trace of the kinetics, which was determined by the dry weight technique in $\mathrm{g} / \mathrm{l}$, where it was observed that glucose as a source of carbon along a 12-day kinetics allows to reach a maximum concentration of biomass around $1.2 \mathrm{~g} / \mathrm{L}$ (Liang et al., 2009). On the other hand, was evaluated the effect on lipid production by adding $\mathrm{CO}_{2}$ as a carbon source, for which a flow of $6 \mathrm{~L} / \mathrm{min}$ of air was used, which is known to have an approximate composition of $0.03 \%$ of $\mathrm{CO}_{2}$, as well as an addition to the culture medium was made, increasing the concentrations of the gas by $0.33,0.83,1.67$ and $3.33 \%$. As results of experimentation, it was observed that in a 15-day kinetics at a $\mathrm{CO}_{2}$ flow of up to $50 \mathrm{ml} / \mathrm{min}$, growth increases, but in a greater range, the development of $C$. vulgaris is not favoured (Widjaja et al., 2009).

In another investigation was evaluated cell growth under 5 different substrates conditions: glucose, glycerol, acetate and mixtures of glucose-glycerol and glucose-acetate at different concentrations and in autotrophic, heterotrophic and mixotrophic culture media, with which they could observe that the highest cellular concentration was in the mixotrophic medium which was $1.40 \mathrm{~g} / \mathrm{L}$ of the dry weight of the cells, in the heterotrophic medium there was a concentration of $0.75 \mathrm{~g} / \mathrm{L}$ of dry weight and that which had a lower yield was in the autotrophic medium which was $0.40 \mathrm{~g} / \mathrm{L}$ dry weight. Regarding the percentage of lipids synthesized, the highest result was in the heterotrophic medium with a production percentage of $30.58 \%$ and the lowest was achieved in the mixotrophic medium, which was $13.82 \%$, so if what is of interest is increasing the amount of biomass, it is recommended to work with mixotrophic medium (Heredia-Arroyo et al., 2011).

Pigments are among the metabolites that may have a biotechnological application due to their chemical activity, for this reason was evaluated the production of protein and fatty acid pigments, varying the light periods during the growth of the microalgae which were from; from 8:16, 12:12 and 16: $8 \mathrm{~h}$ (light / dark). The results showed that at a period of 12 hours of light and 16 hours there is a significant increase in the concentration of biomass with respect to what was observed in a photoperiod of 8 hours and at the same time at a light intensity of $62.5 \mu \mathrm{mol}$ of photons $/ \mathrm{m}^{2} \mathrm{~s}$ there is a greater biomass production. The decrease observed in the increase in photoperiods in graph $\mathrm{c}$ can be explained due to the phenomenon of photooxidation within the cell (Seyfabadi et al., 2011).

Regarding the quantification of metabolites, it was observed that as the irradiation increased, the concentrations of chlorophylls decreased and the concentration of $\beta$-carotenes increased, which makes sense since they are synthesized as a defense mechanism and adaptation to high light exposure by another. On the other hand, the increase in irradiation decreased with respect to the treatments in which there was not a high amount of light because this factor accelerates cell growth, however, this does not mean that it increases the synthesis of pigments so that the accumulation does not it is proportional to the increase in size in the cell. Regarding protein synthesis, it was observed that in the longest and most intense photoperiods there was a greater presence of proteins since in the $16: 8$ photo period at an intensity of $100 \mu \mathrm{mol}$ photons $/ \mathrm{m}^{2} \mathrm{~s}$, a concentration of $46 \%$ protein with respect to cell composition, for which factors play an important role depending on the type of metabolite that is of interest.

Under the production of these metabolites, biodiesel production can be used with the synthesized lipids since the microalgae accumulates large amounts and, in addition to the starch generated, significant concentrations of bioethanol can be obtained, regarding consumption human, it can be used as a food supplement, natural and as an emulsifier, however, what has to be worked on is the increase in the production of metabolites so that it is affordable (Safi et al., 2014).

With the researches analyzed, it is possible to argue that the C. vulgaris microalgae is a microrganism that can be widely applied at the biotechnological level, since they have a considerable production of secondary metabolites depending on the type of substrate they consume; such as lipids and proteins where lipids can be used as raw material for biofuel synthesis where production control is important, which is recommended to be done in closed systems and above all to apply high standards of safety and evaluation of risks (Villareal et al., 2020). On the other hand, with the production of proteins it is possible to give a utility for the elaboration of functional foods enriched with this compound, however, for the production of proteins, it has been observed that the yields vary depending on the culture medium available to the microalgae. and in those who have organic substrates there is an increase in protein concentrations in the cell (Muñoz-Peñuela et al., 2012).

Based on this research, it is possible to formulate a research project in which, through the control of factors such as light, type of substrate, $\mathrm{CO}_{2}$ and oxygen, and even the design of the photobioreactor, the optimization of the growth and generation of primary and secondary metabolites such as those mentioned above. With those analyzed in this review, it is suggested that for the optimization of C. vulgaris cell growth, the use of a photobioreactor is recommended, in which it is possible to place sensors to monitor oxygen, temperature, $\mathrm{pH}$, light intensity through the growth medium and flow regulators, in addition to the fact that an LED light source can be placed inside the photobioreactor and the light path is from the inside to the outside. This design also includes a $\mathrm{CO}_{2}$ gas diffuser with which, in addition to an organic source in the mixotrophic medium, inorganic carbon is kept and contributes to a higher yield in the production of biomass and final compounds. With the design of this photobioreactor, the intention is to use an agitation system by bubbling as agitation where it allows a correct mass transfer in the gas and also the microalgae can be in contact with the substrate in the culture medium. This parameter has already been analyzed previously where through 3 diffusers at different diameters of the sprinkler $(1,2$ and $3 \mathrm{~mm})$ it was observed that the smaller the diameter of the diffuser there is a higher growth rate and that the decrease in the size of Bubble promotes mass transfer between the gas-liquid phase (Doncel \& Moreno, 2020).

Finally, for the application of C. vulgaris under this photobioreactor proposal, it has been observed that the initial concentration in the inoculum of the kinetics is important to be able to observe an adequate growth over time. That is why in 
previous works three inoculum conditions were evaluated in initial kinetics taking a concentration of $1 \times 10^{6}$ cells $/ \mathrm{mL}, 2 \times 10^{6}$ cells $/ \mathrm{mL}$ and $5 \times 10^{6} \mathrm{cells} / \mathrm{mL}$ where it was observed that in the highest initial concentration there was a time of doubling of $7.5 \mathrm{~h}$ differs from those obtained in the lower concentrations that were $59 \mathrm{~h}$ and $23.5 \mathrm{~h}$ respectively, so this condition is recommended to shorten generation times, have a higher yield of primary and secondary metabolites as well as biomass and with the decrease in growth time, the availability of substrates for other microorganisms that may be contaminating is decreased (Rodas-Gaitán et al., 2012).

Within the review carried out, the need has arisen to analyze the secondary metabolites that may have activity as antioxidants because, being photosynthetic organisms with pigments, it is possible that C. vulgaris contains them and of which it has been studied in depth. One of the works that has been carried out regarding this aspect is in which the antioxidant activity and the physiological response of the microalgaeC. vulgaris exposed to phenanthrene were evaluated, however, the work was evaluated for the enzymatic capacity of the microalgae to see the effect on cell density in the medium, chlorophyll content $\mathrm{a}$ and $\mathrm{b}$ and the enzymatic activity of superoxide dismutase and catalase throughout seven-day growths and where it was observed that the enzymes decreased in their activity by free radicals generated by phenanthrene, however, the measured physiological responses did not decrease significantly since in the optical density there was a decrease at the end of the kinetics from $3 \times 10^{8}$ cells $/ \mathrm{mL}$ to $2 \times 10^{8}$ cells $/ \mathrm{mL}$ with the highest concentration of phenanthrene tested, the chlorophyll concentrations were decreased and an increase in the activity of the enzymes, therefore it is concluded that it is a highly resistant microalgaeto different stress conditions. As previously mentioned, the antioxidant response of the microalgae was evaluated, but it is known that organisms, and especially photosynthetics, have the ability to produce pigments or compounds that serve as a defense when they have stressful situations, so that based on this, it is proposed that if there is a control in the growth of the microalgae and an increase in cellular yield, the extraction of metabolites that have inhibition of synthetic free radicals can be done (Calderón-Delgado et al., 2020).

With the completion of a photobioreactor that covers all the aforementioned aspects, it will be possible to control growth conditions and increase product yields, giving a variant application to each of them at a biotechnological and even pharmaceutical level, since the objectives of the work were achieved. This area can be considered, since in carcinogens extractions have been carried out in the Chlorella genus to combat dengue serotype 2 (DENV-2), this extraction was done with temperatures. In addition to these compounds, soluble carbohydrates were extracted from the microalgae in a water bath. Both extracts significantly decreased the growth of the virus, so it is interesting to do a more exhaustive analysis in the identification of all the compounds contained in the extracts and see which of them is the direct inhibitor (Mayta-Huatuco et al., 2020).

It is for them that it is necessary to expand the knowledge of the microalgae C. vulgaris, to design equipment with which to increase the yields of final products and biomass, to shorten cell duplication times and to characterize, isolate and analyze the metabolites in the microalgae to be able to give a direct and specific use as it can be seen that it is an important source of various chemical compounds.

\section{Biodiesel}

Because the lipid content in the microalgae is within a range of 20 to $50 \%$ of the dry weight in the biomass generated, it is considered an important source for the generation of biodiesel, however, it is estimated that the operating costs and generation of this fuel are up to 10 times greater than those generated by obtaining crude oil, since the nutrients necessary for the growth of the microalgae are expensive (He et al., 2013), so it is convenient to optimize growth due to the effect of other factors, such as: the light, the temperature or the inorganic carbon source available to the microalgae, and even the use of media with nutritive loads that can be reused by these micro-organisms, such as those contained in wastewater. In previous investigations the growth of $C$. vulgaris has been evaluated under nutrient limitations and even under saline stress, where it has been observed that in those media where there is a saline concentration $(\mathrm{NaCl})$ around $0.06 \mathrm{M}$ to $0.4 \mathrm{M}$, the percentage of the lipid content in the biomass can reach a concentration of $49 \%$ at the highest salt concentration, and where there was an increase in the concentration of palmitic acid (37\%), oleic acid (15.5\%) and linoleic acid (20\%) making this generated profile suitable for biodiesel production (Pandit et al., 2017).

\section{Biogas}

Current global energy demands have led to the search for alternative sources to cover them, making the generation of biogas a viable option for this. Research has shown that the use of microalgae for the generation of this fuel is beneficial compared to fossil fuels; however, maintaining the growth of the microalgae and the operations involved raise the cost of production, so it is necessary to expand research in this area. Based on the biomass of the microalgae, it is possible to produce biodiesel and biogas due to the type of lipids it produces (Mata et al., 2010).

Previous investigations have carried out the energy comparison of the biomass of $C$. vulgaris grown in a heterotrophic medium with respect to the energy power of biodiesel and biogas (biomethanol) generated from the same microalgae, it has been found that the biomass of $C$. vulgaris has a high energy value compared to the other two fuels, being $24,538 \pm 182 \mathrm{~kJ} / \mathrm{kg}$ which have a value equivalent to the calorific value provided by oil, being $58.4 \%$, making this source of organic material convenient and competitive and it can even be analyzed in depth to optimize biomass production and therefore generate a greater fuel load (Sakarika \& Kornaros, 2018).

\section{Cosmetology}

The applications that $C$. vulgaris has are diverse, since it can be used to cover the energy demands at an industrial level, the health area and even in cosmetology for the compounds it synthesizes, such as lutein, which is a xanthophyll. It represents a potential role in the prevention of retinal degeneration, some types of cancer and cardiovascular diseases due to its antioxidant 
activities (Arnal et al., 2009). That is why some way of extracting this compound without damaging it has been sought, for which the effect of temperature $\left(10^{\circ} \mathrm{C}\right.$ to $\left.40^{\circ} \mathrm{C}\right)$ during the extraction process and by assistance with pulses of electric fields (from $10 \mathrm{kV} / \mathrm{cm}$ to $25 \mathrm{kV} / \mathrm{cm}$ ) and, where, it could be concluded through the response surface methodology that at a temperature around the cultivation temperature of C. vulgaris $\left(30^{\circ} \mathrm{C}\right)$ there was an increase in extraction, since it allows a greater migration of the compound to the outside without affecting it, at an intensity of the electric field of $25 \mathrm{kV} / \mathrm{cm}$, the latter being the highest point of evaluation in the methodology, so it could also be concluded that this technique allows an increase in the extraction of lutein for its biotechnological application and leaves the possibility of further exploring the methodology since the point of greatest extraction, in terms of the electric field, was evaluated as the highest point in the experimental condition, so a greater range can be evaluated to analyze if it is possible to increase the yield of the extraction (Luengo et al., 2015).

On the other hand, the biomass drying condition has been evaluated in the recovery of active compounds to be subsequently extracted, since it is considered that this biomass drying stage is of importance so that most of the active compounds do not degrade. As part of the drying techniques, lyophilization compared to air drying has been proposed and evaluated, to subsequently apply extraction techniques such as those assisted by ultrasound using polar solvents such as water and ethanol. With this methodology, the conservation of pigments such as carotenoids and chlorophylls has been achieved with higher yield in those samples where the biomass was dried by lyophilization since the damage was less in the active compounds. Regarding extraction, it was observed that it is ideal for obtaining the compounds and that ethanol as a solvent allowed high yields in addition to the fact that, as it is not a highly toxic solvent, it allows its application for consumption or in products aimed at the areaof cosmetology (Stramarkou et al., 2017).

Finally, it can be mentioned that the compounds characterized in C. vulgaris have a protective effect for the skin (wrinkles and sagging) as well as protection against UV radiation; however, there is still an extensive study to be done. These characteristics in microalgae are due to the fact that they are microorganisms that during their growth are exposed to oxidative stress conditions, so they must synthesize compounds that allow their protection and survival, such as carotenoids, so the incorporation of microalgae in the formulation of cosmetic products is made to serve as thickeners, water binding agents and antioxidants; however, each species of microalgae is different in its chemical composition and therefore in the applications that can be given in different products, so it is necessary to continue with the investigations in terms of synthesis, characterization, extraction and purification of active compounds (Ariede et al., 2017).

\section{Supplementary food}

As the microalgae are rich sources of protein, lipids, carbohydrates and some pigments, it turns them into a source with high nutritional value, so it is important to increase the studies to optimize the growth of the microalgae and thus obtain a higher concentration of biomass to through the best growing conditions; However, these factors depend on the type of compound that you want to produce (proteins, lipids, carbohydrates or pigments) since these are influenced depending on the condition of the culture (Tandon \& Jin, 2017). In recent years, the extraction, characterization and application of the metabolites produced by C. vulgaris have been carried out for use in the formulation of food supplements, where it is important to analyze the extraction process. In 2018, the selection of the pigment and protein extraction process generated by $C$. vulgaris was analyzed through selective extraction of carotenoids and chlorophylls using ethanol as solvent, followed by an extraction treatment at alkaline $\mathrm{pH}$ for extraction of proteins from the wet biomass. Within the pigments extracted with ethanol, lutein and total chlorophyll (chlorophyll a and chlorophyll b) could be identified, achieving a yield of $5.4 \mathrm{mg} / \mathrm{g}$ and $15.4 \mathrm{mg} / \mathrm{g}$ of dry biomass, and where the proteins could be extracted from the medium by proposed alkaline $\mathrm{pH}$, concentrating and fractionating them through membranes in which the proteins were selective for a size of $300 \mathrm{kDa}$, so it was observed that under this method of pigment extraction with a polar solvent and in an alkaline medium, it has high yields and the metabolites are not affected (Kulkarni \& Nikolov, 2018).

It is known that there is a great variety of microalgae in the world and which can be used depending on the type of products or metabolites that you want to obtain, as well as the growth conditions that each one requires; However, $C$. vulgaris is considered one of the best for its easy adaptability and performance in the products generated during growth. Among the comparisons that have been made of $C$. vulgaris with other microalgae, we can mention those made against Spirulina maxima, C. vulgaris (orange), Haematococcus pluvialis, Diacronema vlkianum and Isochrysis galbana where it has been observed that the $\%$ of weight Dry is less in C. vulgaris and S. maxima with respect to the others; however, its protein content is very close (38\%) to that reported in Diacronema vlkianum (38.4\%) and Isochrysis galbana (39.6\%), and due to the failure of S. maxima (44.9\%), making it competent as a protein source. Regarding lipid compression, it has been observed that there is a low concentration in S. maxima and C. vulgaris (3.6\% and $5.1 \%)$ and its carbohydrate content is in a medium range, being $19.9 \%$, so this reinforces its application as a food supplement (Batista et al., 2013).

Improvements have recently been made in the production of vitamins, such as vitamin B12, through C. vulgaris since this microalgae is rich in vitamin B12 and cobalt ions which are at the center of the vitamin, therefore, through the growth of the microalgae in media exposed to different concentrations of cobalt chloride salts, it has been evaluated whether there is an increase in the production of the vitamin. The growth was also carried out with $\mathrm{CO}_{2}$ as a source of inorganic carbon and the concentrations at which it has been evaluated, so far this growth is concentration of cobalt salt of $0.5,1.5,2$ and $2.5 \mu \mathrm{M}$ obtaining an increase in the rate growth rate of $C$. vulgaris under the condition of $2.5 \mu \mathrm{M}$, with a biomass concentration of $173.32 \pm 4.23 \mu \mathrm{g} / 100 \mathrm{~g}$ of dry biomass, which represented an increase of $12 \%$ compared to the control where cobalt salts were not applied and with which it could be observed that there was an increase in the final production of vitamin B12 (Jalilian et al., 2019). 
Undoubtedly, the application of C. vulgaris in this area is for the synthesis, extraction and purification of proteins, for which, over the years, research has been intensified as to the optimal conditions under which the microalgae it can grow and thus increase the yields in the production of this metabolite; however, the methods by which these protein components are extracted are of interest to avoid degradation during the processes. It is for them that research has recently been carried out in which new extraction methods are proposed, such as ultrasound assistance using a single solvent, different solvents sequentially and even enzymes, where, within the solvents used, $\mathrm{NaOH}$ and $\mathrm{HCl}$ can be mentioned, and among the enzymes used, lysozyme and proteases are mentioned, and where, it could be observed that the sequence extraction with solvents and the enzymatic extraction increased the recovery performance of protein and even free amino acids, being $79 \%, 33 \%$ to $42 \%$ and $58 \%$ to $82 \%$ respectively, so the use of enzymes of the protease type for extraction through ultrasound is significant to improve the recovery of enzymes synthesized by $C$. vulgaris and be able to add it to a functional type of food (Hildebrand et al., 2020).

\section{Bioremediation}

C. vulgaris, like other species of microalgae, are microgamisms that are easily adaptable to different growth media, and can therefore be used for wastewater treatment. Among the applications that may have in this topic are wastewater treatments in the textile industry, where, through growth in concentrated waters with the waste generated in a range of $5 \%$ to $17.5 \%$, it was observed that C. vulgaris was able to adapt to the environment by generating significant amounts of biomass and reducing the colour load by up to $75.68 \%$ and the chemical oxygen demand (COD) with a $69 \%$ elimination in the most concentrated media, making it recommendable for the treatment of this type of water (El-Kassas \& Mohamed, 2014).

As previously mentioned, for the treatment of wastewater to be successful, a correct removal of nutrients is necessary, for which work has been carried out with C. vulgaris, where the removal of nutrients in standard water, water has been evaluated. primary and secondary waste and even in wastewater with oil, observing that the nutrients contained in the primary and secondary wastewater as well as in those with oil provide a balance of nutrients to promote the growth of the microalgae, reaching a concentration of 13 days maximum of $1.6 \mathrm{~g} / \mathrm{L}$ of biomass, which shows the adaptability of $C$. vulgaris and the removal of nutrients in different media (Znad et al., 2018).

In addition to the removal of organic nutrients, it has been observed and evaluated that C. vulgaris is useful for the removal of heavy metals in culture medium, among the metals that have been evaluated, work has been done with lead, which is one of the main water pollutants and the most dangerous for humans. That is why, through research, the growth of $C$. vulgaris exposed to different concentrations of lead and how the absorption of this metal through the microalgae is evaluated. The conditions evaluated were in a control medium without the presence of metal and three other media at a concentration of $1 \mathrm{mg} / \mathrm{L}, 3 \mathrm{mg} / \mathrm{L}$ and $5 \mathrm{mg} / \mathrm{L}$ of lead during 7-day growth kinetics: At the end of the kinetics of growth it was observed that in the medium of $1 \mathrm{mg}$ / L there was a final concentration of $0.1453 \mathrm{mg} / \mathrm{L}$, in the medium with a concentration of $3 \mathrm{mg} / \mathrm{L}$ of lead there was a final concentration of $0.4144 \mathrm{mg} / \mathrm{L}$ and in the last medium concentration of $5 \mathrm{mg} / \mathrm{L}$ there was a presence of $0.5305 \mathrm{mg} / \mathrm{L}$ of lead so it can be concluded that C. vulgaris is useful for the absorption of lead and therefore removal of heavy metal. This same work revealed that growth was not affected since there was a final concentration of cells of 829.0012 X $10^{4}$ cells / ml, 1069.9446 $\mathrm{X} 10^{4}$ cells / $\mathrm{ml}$ and $808.94450 \mathrm{X} 10^{4}$ cells / ml, so, although an affectation to the higher lead concentration, the growth capacity is not completely inhibited, making it an excellent microorganism for this bioremediation work (Sulistya \& Nuravivah, 2018).

\section{Conclusions}

C. vulgaris, undoubtedly, is one of the microalgae that can be given a reality in the current research, since this microalgae is directly influenced in its growth and production of primary and secondary metabolites by the conditions to which it is during its development, it is for them that it is important to analyze, design, build and execute systems with the necessary parameters that can have the highest production yields and thus be able to formulate products with biotechnological application that are profitable and Affordable It can also be concluded that this microalgae is ideal to increase production since its chemical composition can generate various products, from food to energy and where it is important that it be an easily adaptable microorganism and that it can carry out metabolisms diverse; whether they are autotrophic, heterotrophic or both at the same time, so it gives a great advantage over the rest of the microalgae.

\section{Acknowledgements}

We thank the partial donations to the Project: Efecto de la fuente de sustrato sobre las cinéticas de crecimiento de Chlorella vulgaris a nivel matraz., with the Convocatoria de Proyectos de Desarrollo Tecnológico e Innovación para Estudiantes, 2020 (8959.20-P) and Convocatoria de Proyectos de Investigación Científica, 2020 (7662.20-P), Tecnológico Nacional de México / Instituto Tecnológico de Morelia. We also appreciate the participation of the Consejo Nacional de Ciencia y Tecnología" (CONACyT) through the financial support of the Scholarship 0456297331 (Jesús Alberto Coronado-Reyes).

\section{References}

Acién Fernández, F. G., González-López, C. V., Fernández Sevilla, J. M., \& Molina Grima, E. (2012). Conversion of $\mathrm{CO}_{2}$ into biomass by microalgae: how realistic a contribution may it be to significant $\mathrm{CO}_{2}$ removal? Applied Microbiology and Biotechnology, 96(3), 577586. http://dx.doi.org/10.1007/s00253-012-4362-z. PMid:22923096.

Andrade, E., Souza, D., \& Colozzi, A. (2014). Non-photoautotrophic cultivation of microalgae: an overview. Ciências Biológicas e da Saúde (Londrina), 35(2), 115-134.

Ardila-Álvarez, A., López-Matos, Y., Vásquez-Cáceres, M., GónzalezDelgado, Á., \& Barajas-Solano, A. (2017). Obtainig lipids and carbohydrates from microalgae via design of selective culture media. TecnoLógicas, 20(38), 83-94. 
Ariede, M., Marcílio, T., Morocho, A., Robles, M., Carvalho, J., \& Rolim, A. (2017). Cosmetic attributes of algae - A review. Algal Research, 25, 483-487. http://dx.doi.org/10.1016/j.algal.2017.05.019.

Arnal, E., Miranda, M., Johnsen-Soriano, S., Alvarez-Nolting, R., Diaz-Llopis, M., Araiz, J., Cervera, E., Bosch-Morell, F., \& Romero, F. J. (2009). Beneficial effect of docosahexanoic acid and lutein on retinal structural,metabolic, and functional abnormalities in diabetic rats. Current Eye Research, 34(11), 928-938. http://dx.doi. org/10.3109/02713680903205238. PMid:19958109.

Bartley, M., Boeing, W., Dungan, B., Holguin, F., \& Schaub, T. (2013).pH effects on growth and lipid accumulation of the biofuel microalgae Nannochloropsis salina and invading organisms. Journal of Applied Phycology, 26(3), 1431-1437. http://dx.doi.org/10.1007/s10811013-0177-2.

Batista, A., Gouveia, L., Bandarra, N., Franco, J., \& Raymundo, A. (2013). Comparison of microalgal biomass profiles as novel functional ingredient for food products. Algal Research, 2(2), 164-173. http:// dx.doi.org/10.1016/j.algal.2013.01.004.

Calderón-Delgado, I. C., Mora-Solarte, D. A., \& Velasco-Santamaría, Y. M. (2020). Physiological responses and antioxidant capacity of Chlorella vulgaris (Chlorellaceae) exposed to Phenanthrene. Acta Biologica Colombiana, 25(2), 225-234. http://dx.doi.org/10.15446/ abc.v25n2.77783.

Casierra-Posada, F. (2007). Fotoinhibición: Respuesta fisiológica de los vegetales al estrés por exceso de luz. Revista Colombiana de Ciencias Horticolas, 1(1), 114-123. http://dx.doi.org/10.17584/ rcch.2007v1i1.1150.

Chinnasamy, S., Ramakrishnan, B., Bhatnagar, A., \& Das, K. (2009). Biomass Production Potential of a Wastewater Alga Chlorella vulgaris ARC 1 under Elevated Levels of $\mathrm{CO}_{2}$ and Temperature. International Journal of Molecular Sciences, 10(2), 518-532. http:// dx.doi.org/10.3390/ijms10020518. PMid:19333419.

Contreras, C., Peña, J., Flores, L., \& Cañizares, R. (2003). Avances en el diseño conceptual de fotobiorreactores para el cultivo de microalgas. Interciencia, 28(8), 450-456.

Coronado-Reyes, J. (2020). Modelo para la cinética de crecimiento de la microalga Chlorella vulgaris en fotobiorreactor evaluando las variables eléctricas y bioquímicas óptimas mediante el método de Taguchi (Thesis in progress). Tecnológico Nacional de México, Instituto Tecnológico de Morelia, México.

Godos, Id., Blanco, S., García-Encina, P. A., Becares, E., \& Muñoz, R. (2009). Long-term operation of high rate algal ponds for the bioremediation of piggery wastewaters at high loading rates. Bioresource Technology, 100(19), 4332-4339. http://dx.doi.org/10.1016/j. biortech.2009.04.016. PMid:19427783.

Doncel, J., \& Moreno, H. (2020). Evaluación de la influencia de la agitación para la producción de biomasa microalgal en un fotobiorreactor panel plano a escala laboratorio. Mutis, 10(1), 1-18.

El-Kassas, H. Y., \& Mohamed, L. A. (2014). Bioremediation of the textile waste effluent by Chlorella vulgaris. Egyptian Journal of Aquatic Research, 40(3), 301-308. http://dx.doi.org/10.1016/j.ejar.2014.08.003.

Grobbelaar, J. (2004). Algal nutrition: mineral nutrition. Iowa: Richmond A.

He, P., Mao, B., Shen, C., Shao, L., Lee, D., \& Chang, J. (2013). Cultivation of Chlorella vulgaris on wastewater containing high levels of ammonia for biodiesel production. Bioresource Technology, 129, 177-181. http://dx.doi.org/10.1016/j.biortech.2012.10.162. PMid:23246758.

Heredia-Arroyo, T., Wei, W., Ruan, R., \& Hu, B. (2011). Mixotrophic cultivation of Chlorella vulgaris and its potential application for the oil accumulation from non-sugar materials. Biomass and Bioenergy, 35(5), 2245-2253. http://dx.doi.org/10.1016/j.biombioe.2011.02.036.
Hernández-Pérez, A., \& Labbé, J. (2014). Microalgas, cultivo y beneficios. Revista de Biología Marina y Oceanografía, 49(2), 157-173. http:// dx.doi.org/10.4067/S0718-19572014000200001.

Hildebrand, G., Poojary, M., O’Donnell, C., Lund, M., García-Vaquero, M., \& Tiwari, B. (2020). Ultrasound-assisted processing of Chlorella vulgaris for enhanced protein extraction. Journal of Applied Phycology, 32(3), 1709-1718. http://dx.doi.org/10.1007/s10811-020-02105-4.

Ho, S., Chen, C., Lee, D., \& Chang, J. (2011). Perspectives on microalgal $\mathrm{CO}_{2}$-emission mitigation systems - A review. Biotechnology Advances, 29(2), 189-198. http://dx.doi.org/10.1016/j.biotechadv.2010.11.001. PMid:21094248.

Jalilian, N., Najafpour, G., \& Khajouei, M. (2019). Enhanced Vitamin B12 Production using Chlorella vulgaris. International Journal of Engineering, 32(1), 1-9.

Kai, I., Yik, Y., Jusoh, M., Abdul, W., \& Nagappan, T. (2020). Chlorella vulgaris: a perspective on its potential for combining high biomass with high value bioproducts. Applied Psychology, 1(1), 2-11.

Kulkarni, S., \& Nikolov, Z. (2018). Process for selective extraction of pigments and functional proteins from Chlorella vulgaris. Algal Research, 35, 185-193. http://dx.doi.org/10.1016/j.algal.2018.08.024.

Kunjapur, A., \& Eldridge, R. (2010). Photobioreactor design for commercial biofuel production from Microalgae. Industrial \& Engineering Chemistry Research, 49(8), 3516-3526. http://dx.doi.org/10.1021/ ie901459u.

Liang, Y., Sarkany, N., \& Cuí, Y. (2009). Biomass and lipid productivities of Chlorella vulgaris under autotrophic, heterotrophic and mixotrophic growth conditions. Biotechnology Letters, 31(7), 1043-1049. http:// dx.doi.org/10.1007/s10529-009-9975-7. PMid:19322523.

Lu, W., Wang, Z., Wang, X. \& Yuan, Z. (2015). Cultivation of Chlorella sp. using raw diary wastewater for nutrient removal and biodiesel production: characteristics comparison of indoor bench-scale and outdoor pilot-scale cultures. Bioresource Technology, 1, 1-31.

Luengo, E., Martínez, J., Bordetas, A., Álvarez, I., \& Raso, J. (2015). Influence of the treatmentmediumtemperature on lutein extraction assisted by pulsed electric fields from Chlorella vulgaris. Innovative Food Science \& Emerging Technologies, 29, 15-22. http://dx.doi. org/10.1016/j.ifset.2015.02.012.

Mata, T., Martins, A., \& Caetano, N. (2010). Microalgae for biodiesel production and otherapplications: A review. Renewable \& Sustainable Energy Reviews, 14(1), 217-232. http://dx.doi.org/10.1016/j. rser.2009.07.020.

Mayta-Huatuco, E., Mariano, M., Mamani, E., Montoya, H., Sevilla, L., Quispe, B., Gonzales, M., Tarazona, R., Quintana, A., \& Sulca, J. (2020). Extracción y evaluación de compuestos antivirals de Chondracanthus chamissoi y Chlorella peruviana contra el virus dengue serotipo 2. Acta Médica Peruana, 37(1), 11-18. http://dx.doi. org/10.35663/amp.2020.371.957.

Mohamed, A., Abo-El-Khair, A., \& Shalaby, S. (2013). Quality of Novel Healthy Processed Cheese Analogue Enhanced with Marine Microalgae Chlorella vulgaris Biomass. World Applied Sciences Journal, 23(7), 914-925.

Montero-Sánchez, Y., Gallo, A., Gómez, L., Álvarez, I., Sabina, L., Támbara, Y., \& Ramírez, L. (2012). Productividad de lipidos y composición de ácidos grasos de cinco especies de microalgas. Investigación y Saberes, 1(2), 37-43.

Moon, M., Kim, C., Park, W., Yoo, G., Choi, Y., \& Yang, J. (2013). Mixotrophic growth with acetate or volatile fatty acids maximizes growth and lipid production in Chlamydomonas reinhardtii. Algal Research, 2(4), 352-357. http://dx.doi.org/10.1016/j.algal.2013.09.003. 
Morales-Sánchez, D., Martínez-Rodríguez, O., Kyndt, J., \& Martínez, A. (2014). Heterotrophic growth of microalgae: metabolic aspects. World Journal of Microbiology \& Biotechnology, 31(1), 1-9. http:// dx.doi.org/10.1007/s11274-014-1773-2. PMid:25388473.

Muñoz-Peñuela, M., Ramírez-Merino, J., Otero-Paternina, A., MedinaRobles, V., Cruz-Casallas, P., \& Velasco-Santamarina, Y. (2012). Efecto del medio de cultivo sobre el crecimiento y el contenido proteico de Chlorella vulgaris. Revista Colombiana de Ciencias Pecuarias, 25(3), 438-449.

Ohse, S., Bianchini, R., Ávila, R., Villela, M., Cunha, P., Pavan, C., \& Estevão, M. (2008). Crescimento de microalgas em sistema autotrófi co estacionário. Biotemas, 21(7), 7-18.

Pandit, P. R., Fulekar, M. H., \& Karuna, M. S. L. (2017). Effect of salinity stress on growth, lipid productivity, fatty acid composition, and biodiesel properties in Acutodesmus obliquus and Chlorella vulgaris. Environmental Science and Pollution Research International, 24(15), 13437-13451. http://dx.doi.org/10.1007/s11356-017-8875-y. PMid:28386901.

Rodas-Gaitán, H., Rodríguez-Fuentes, H., Flores-Mendiola, G., VidalesContreras, J., Aranda-Ruiz, J., \& Luna-Maldonado, A. (2012). Efecto de la densidad celular de inoculación en el crecimiento de Chlorella vulgarisCLV2 cultivada bajo condiciones mixotróficas. Revista Fitotecnia Mexicana, 35(5), 83-86. http://dx.doi.org/10.35196/ rfm.2012.Especial_5.83.

Safi, C., Zebid, B., Merah, O., Pontalier, P., \& Vaca-García, C. (2014). Morphology, composition, production, processing and applications of Chlorella vulgaris: A review. Renewable \& Sustainable Energy Reviews, 35, 265-278. http://dx.doi.org/10.1016/j.rser.2014.04.007.

Sakarika, M., \& Kornaros, M. (2018). Chlorella vulgaris as a green biofuel factory: comparison between biodiesel, biogas and combustible biomass production. Bioresource Technology, 273, 237-243. http:// dx.doi.org/10.1016/j.biortech.2018.11.017. PMid:30447625.

Seyfabadi, J., Ramezanpour, Z., \& Amini Khoeyi, Z. (2011). Protein, fatty acid, and pigment content of Chlorella vulgaris under different light regimes. Journal of Applied Phycology, 23(4), 721-726. http:// dx.doi.org/10.1007/s10811-010-9569-8.
Shanmugam, S., Mathimani, T., Anto, S., Sudhakar, M., Kumar, S., \& Pugazhendhi, A. (2020). Cell density, Lipidomic profile, and fatty acid characterization as selection criteria in bioprospecting of microalgae and cyanobacterium for biodiesel production. Bioresource Technology, 304, 1-4. http://dx.doi.org/10.1016/j.biortech.2020.123061. PMid:32127245.

Stramarkou, M., Papadaki, S., Kyriakopoulou, K., \& Krokida, M. (2017). Effect of drying and extraction conditions on the recovery of bioactive compounds from Chlorella vulgaris. Journal of Applied Phycology, 29(6), 2947-2960. http://dx.doi.org/10.1007/s10811-017-1181-8.

Sulistya, E., \& Nuravivah, R. (2018). Potential of Microalgae Chlorella vulgaris as bioremediation agents of heavy metal $\mathrm{Pb}$ (Lead) On Culture Media. Web of Conferences, 31(1), 1-4.

Tandon, P., \& Jin, Q. (2017). Microalgae culture enhancement through key microbial approaches. Renewable \& Sustainable Energy Reviews, 80, 1089-1099. http://dx.doi.org/10.1016/j.rser.2017.05.260.

Ursu, A., Marcati, A., Sayd, T., Sante-Lhoutellier, V., Djelveh, G., \& Michaud, P. (2014). Extraction, fractionation 1 and functional properties of proteins from the microalgae Chlorella vulgaris. Bioresource Technology, 157, 134-309. http://dx.doi.org/10.1016/j. biortech.2014.01.071. PMid:24534795

Villareal, J., Burgués, C., \& Rösch, C. (2020). Acceptability of genetically engineered algae biofuels in Europe: opinions of experts and stakeholders. Biotechnology for Biofuels, 13(92), 1-21. PMid:32489422.

Widjaja, A., Chien, C., \& Ju, Y. (2009). Study of increasing lipid production from fresh water microalgae Chlorella vulgaris. Journal of the Taiwan Institute of Chemical Engineers, 40(1), 13-20. http:// dx.doi.org/10.1016/j.jtice.2008.07.007.

Yamamoto, M., Fujishita, M., Hirata, A., \& Kawano, S. (2004). Regeneration and maturation of daughter cell walls in the autospore-forming green alga Chlorella vulgaris (Chlorophyta,Trebouxiophyceae). Journal of Plant Research, 117(4), 257-264. http://dx.doi.org/10.1007/s10265004-0154-6. PMid:15108033.

Znad, H., Al Ketife, A., Judd, S., AlMomani, F., \& Vuthaluru, H. (2018). Bioremediation and nutrient removal from wastewater by Chlorella vulgaris. Ecological Engineering, 110, 1-7. http://dx.doi.org/10.1016/j. ecoleng.2017.10.008 